\title{
Steroid hormones related to $11 \beta$-hydroxysteroid dehydrogenase in obese and non-obese adolescents
}

Ludmila Máčová, Martin Hill, Marie Bičíková, Hana Zamrazilová, Barbora Sedláčková and Luboslav Stárka

Institute of Endocrinology, Národní 8, 11694 Prague 1, Czech Republic

Email:1macova@endo.cz

\section{INTRODUCTION}

- Glucocorticoids (GC) are involved in metabolic processes of the human body

- GC overproduction leads to metabolic disease such as obesity and metabolic syndrome

- The tissue specific enzyme $11 \beta$-hydroxysteroid dehydrogenase type 1 (11ß-HSD 1) amplifies local GC levels by inter-conversion of inactive cortisone to biological active cortisol

- Cortisol production rates by $11 \beta$-HSD 1 are at least equivalent to that of the adrenal glands

- 11ß-HSD 1 converts also 7-hydroxylated metabolites of dehydroepiandrosterone (DHEA) to 7-oxo-DHEA

- Substrates of the enzyme represent potent competitive inhibitors

\section{METHODS/ DESIGN}

282 obese adolescents BMI (Body Mass Index) $>90^{\text {th }}$ percentile related to gender and age:

- 154 girls (median age 15.31, range 14.17-16.68 years)

- 128 boys (median age 14.95 , range $13.87-16.16$ years)

100 normostenic controls BMI $25^{\text {th }}$ to $75^{\text {th }}$ percentile related to gender and age:

- 50 girls (median age 15.29 , range 14.32-16.79 years)

- 50 boys (median age 15.29 , range 14.47-16.77 years)

- Circulating levels of cortisol, cortisone, DHEA, 7-oxo-, 7 $\alpha$-hydroxy-, $7 \beta$-hydroxy- and 16 $\alpha$-hydroxyDHEA

- Body composition: bioimpedance Tanita BC-418 MA

- Steroid hormones: API 3200 (AB Sciex, Concord, Canada) triple stage quadrupole - mass spectrometer with electrospray ionization (ESI) connected to the UPLC Eksigent ultraLC 110 system (Redwood City, CA, USA)

- Statistical analysis: repeated ANOVA followed by least significant multiple comparisons

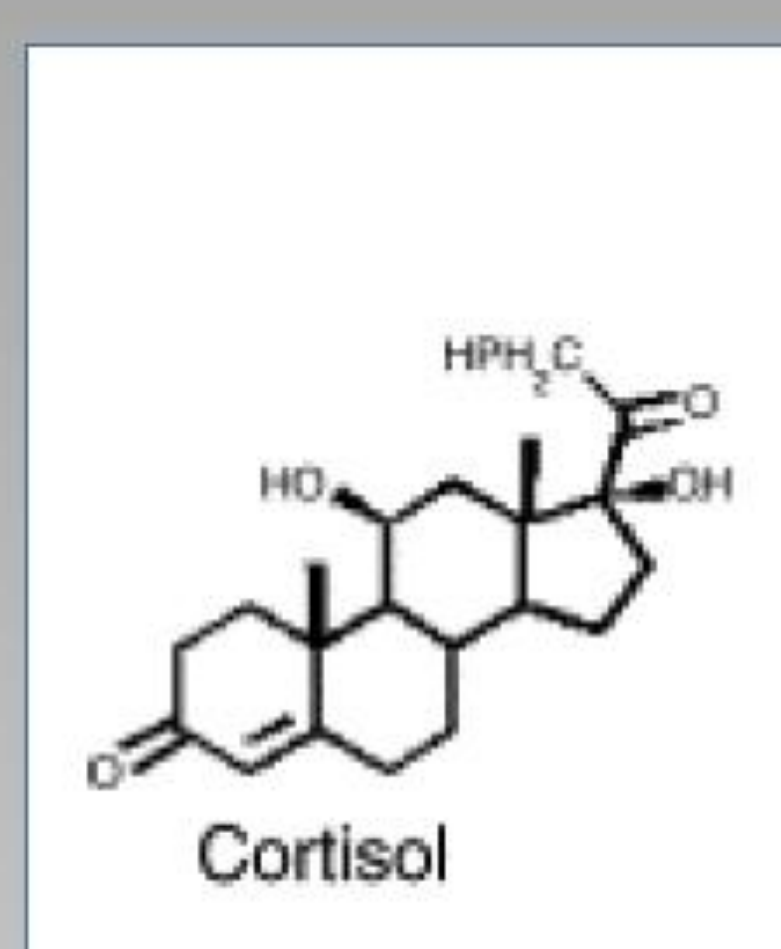

\section{NADP+}
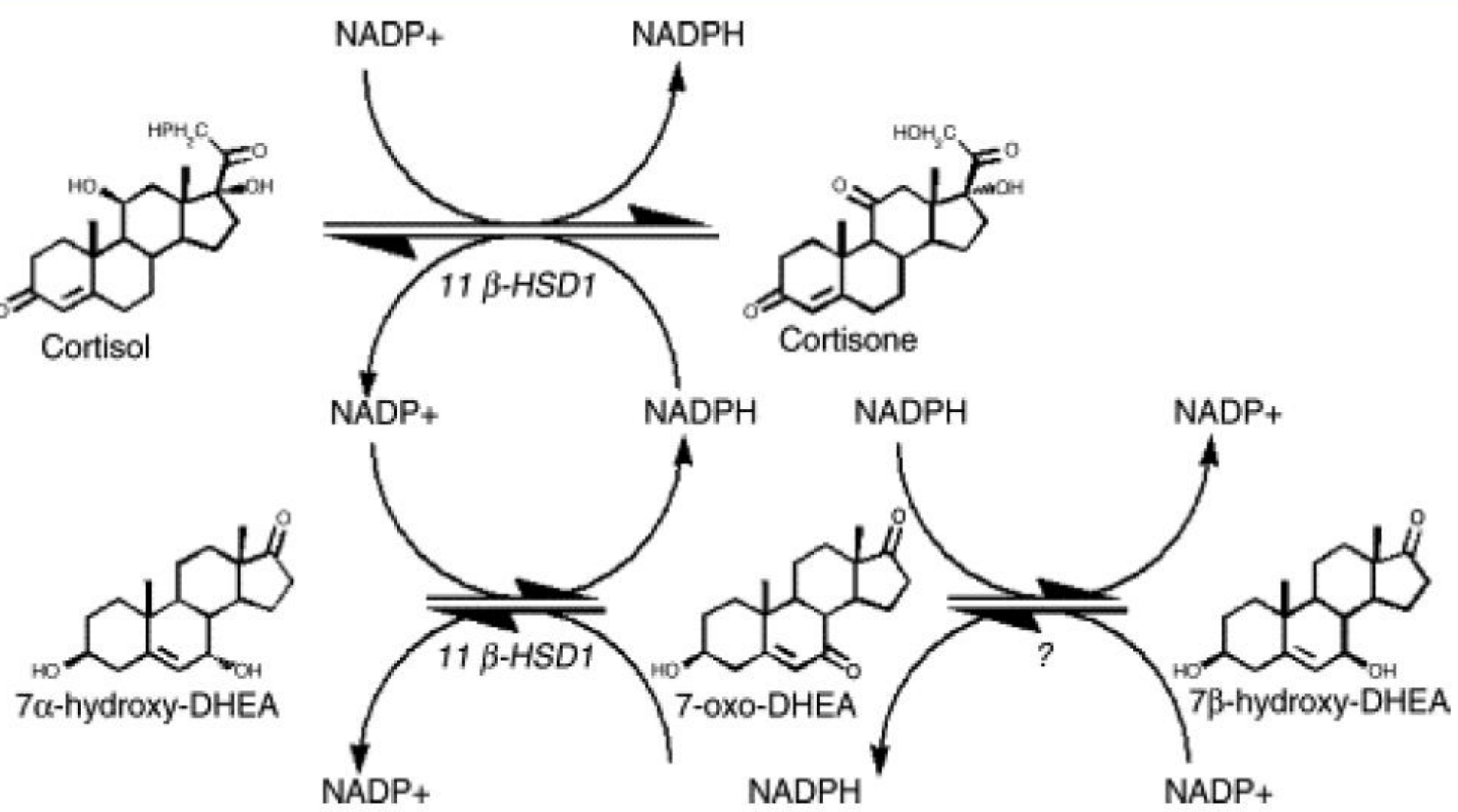

Fig.1 11ß-HSD 1- mediated oxidoreduction of cortisol and $7 \alpha$-hydroxy-DHEA C.Muller et al./ The Journal of Steroid Biochemistry and Molecular Biology 99 (2006) 215-222

\section{AIM OF THE STUDY}

- Examine the circulating levels of steroids related to $11 \beta-H S D 1$ in obese patients and compare them with that of healthy controls

- Try to estimate the role of the $11 \beta$-HSD 1 in obesity

\section{CONCLUSIONS}

- Identical levels of cortisol but increased levels of cortisone indicate an altered activity of $11 \beta$-HSD 1 in obese patients

- This assumption is also supported by significantly higher levels of 7oxo-DHEA

- We do not expect that measured changes in steroid levels caused other enzyme able to metabolize cortisol/cortisone - 11 $\beta$-HSD type 2

- Firstly, 11ß-HSD 2 does not metabolize derivatives of DHEA and secondly, its activity remains unchanged with development of obesity

- Increased local cortisol production in adipose tissue induces likely a compensatory mechanism to maintain whole-body levels balanced

- The mechanism involves the reduction of hepatic $11 \beta$-HSD 1 and the activation of $5 \alpha$-reductase which metabolizes cortisol towards waste products, both observed in obesity

- Considering the prevailing contribution of hepatic $11 \beta$-HSD 1 to extraadrenal cortisol production, we suppose that the presented changes in circulating (neuro)steroid levels were due to altered activity of hepatic $11 \beta$-HSD 1

\section{RESULTS}

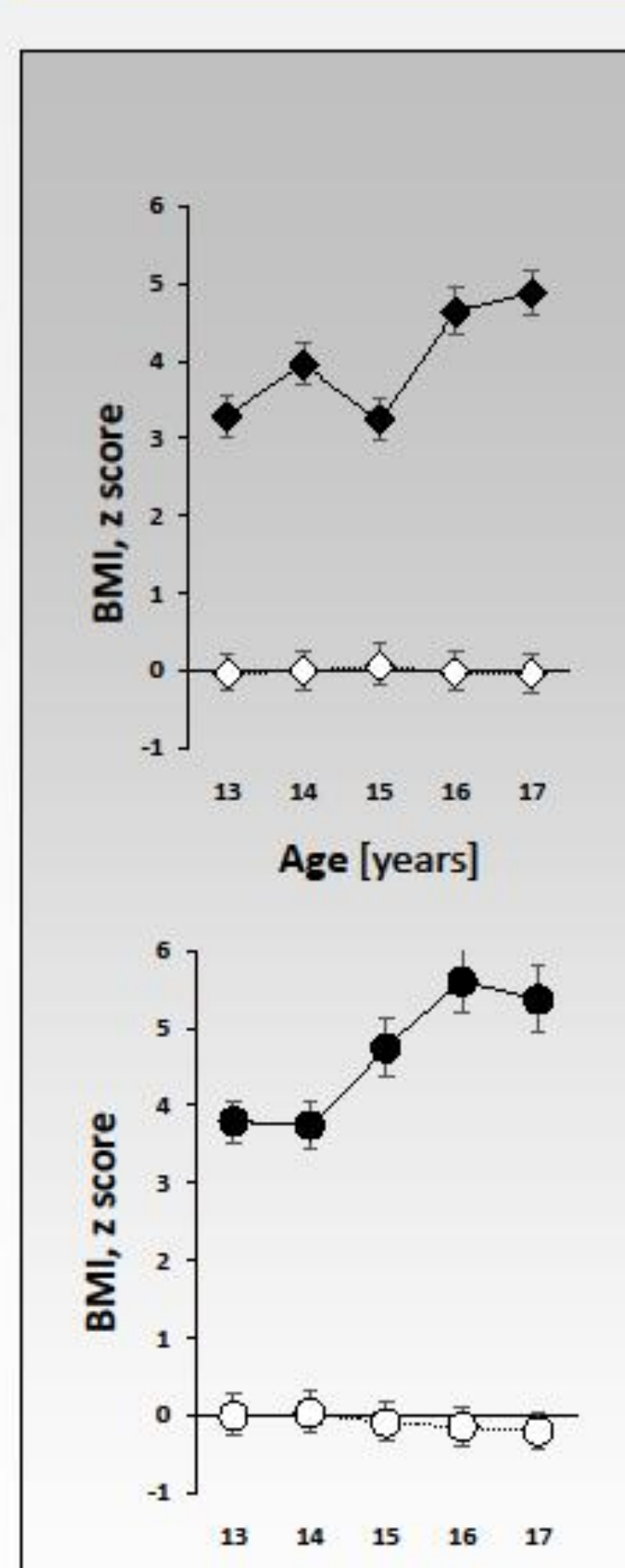

Aze [years]
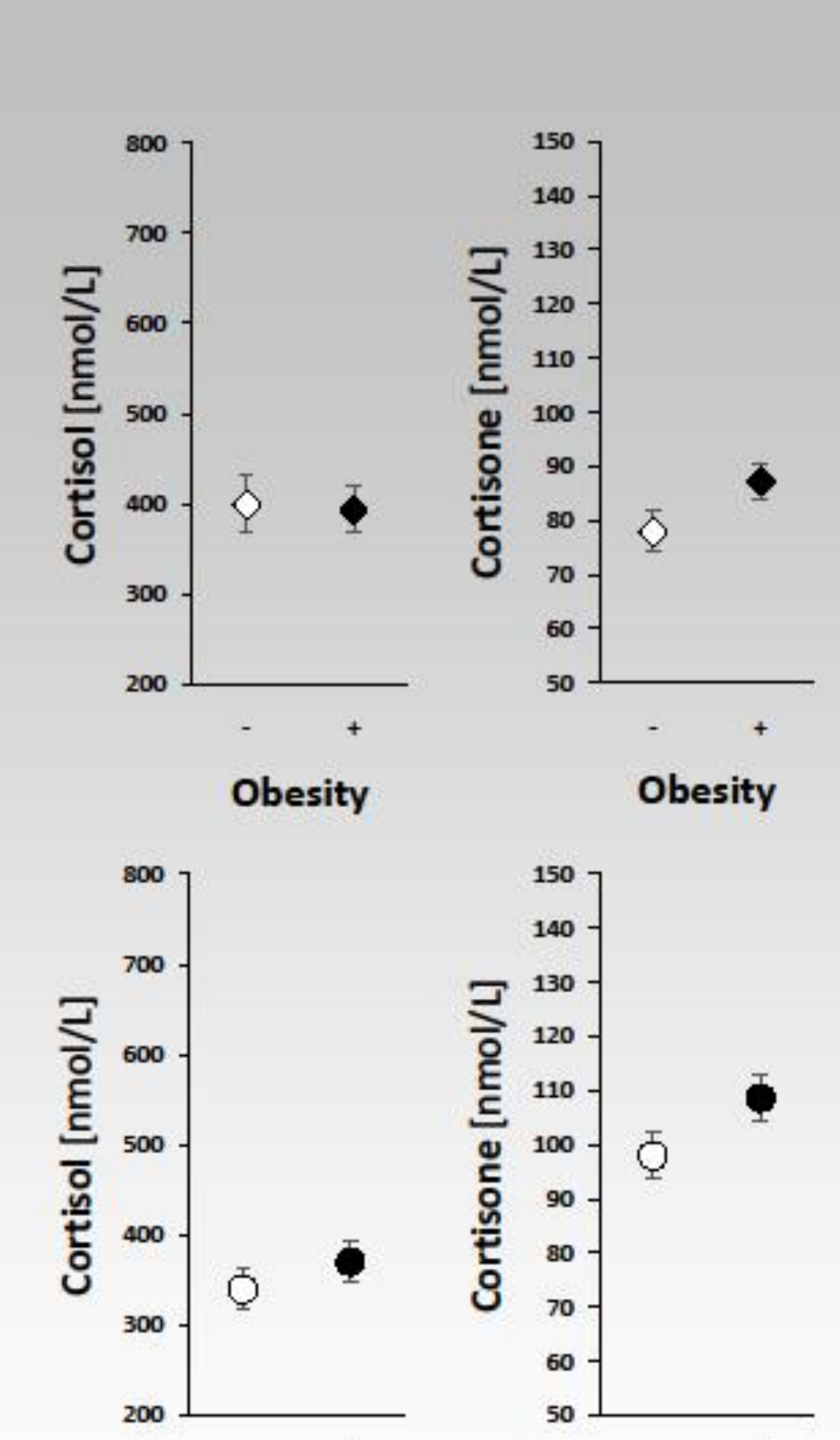

obesity
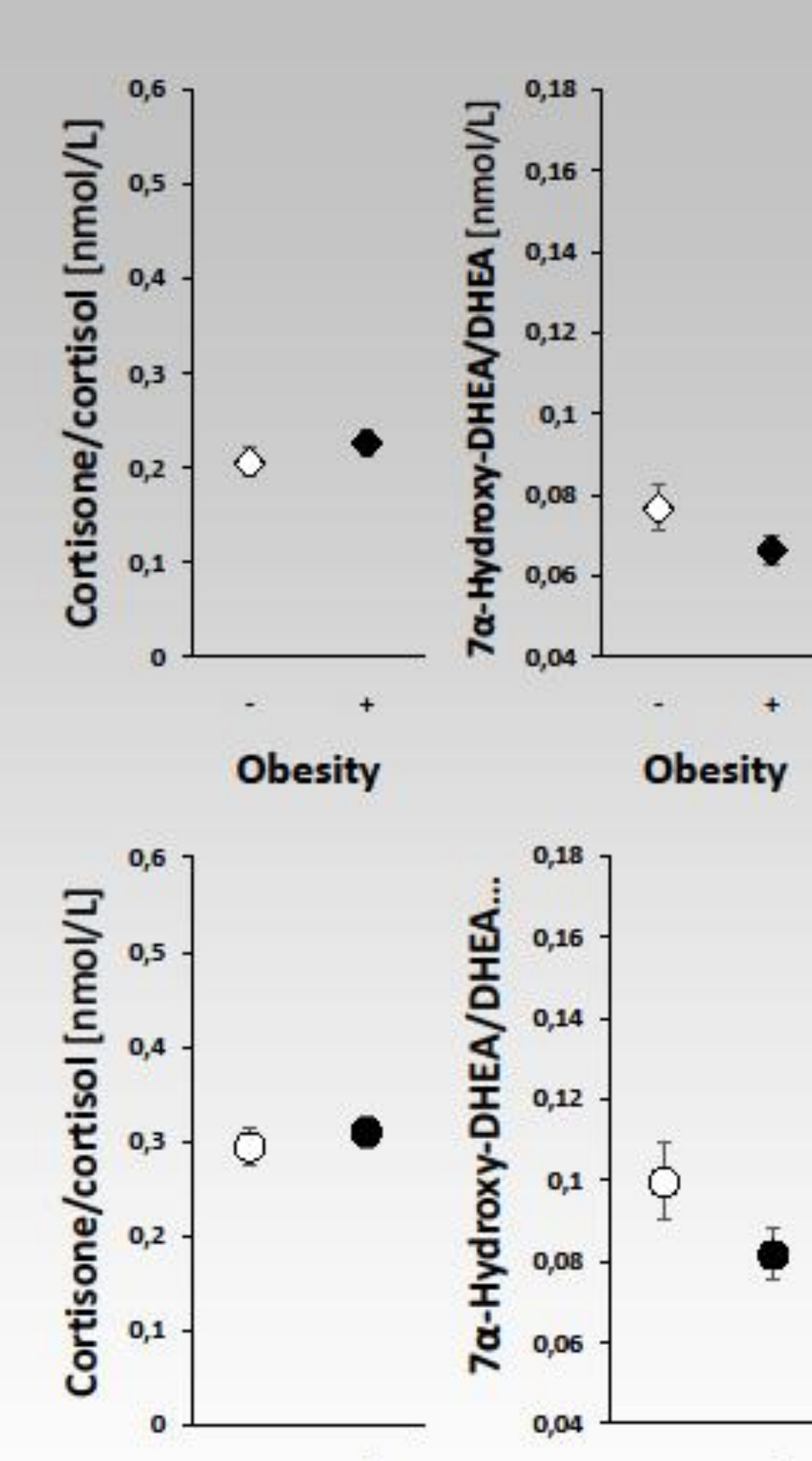

obesity

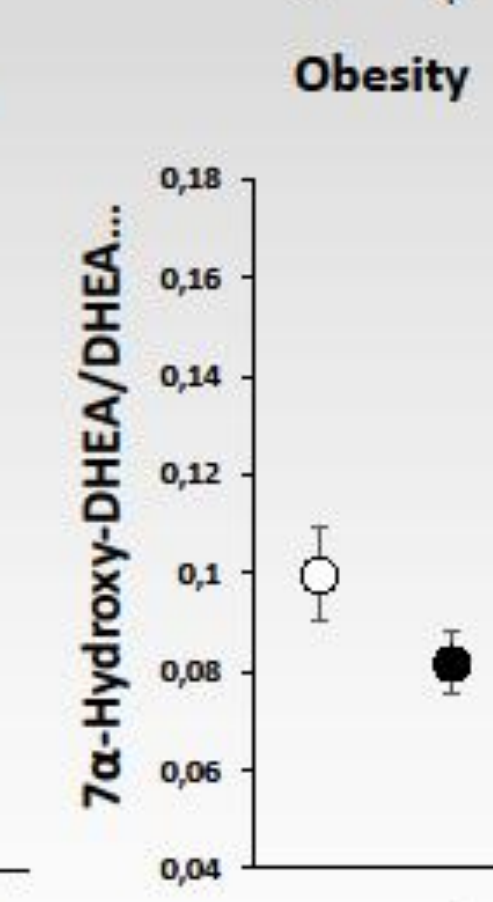

obesity
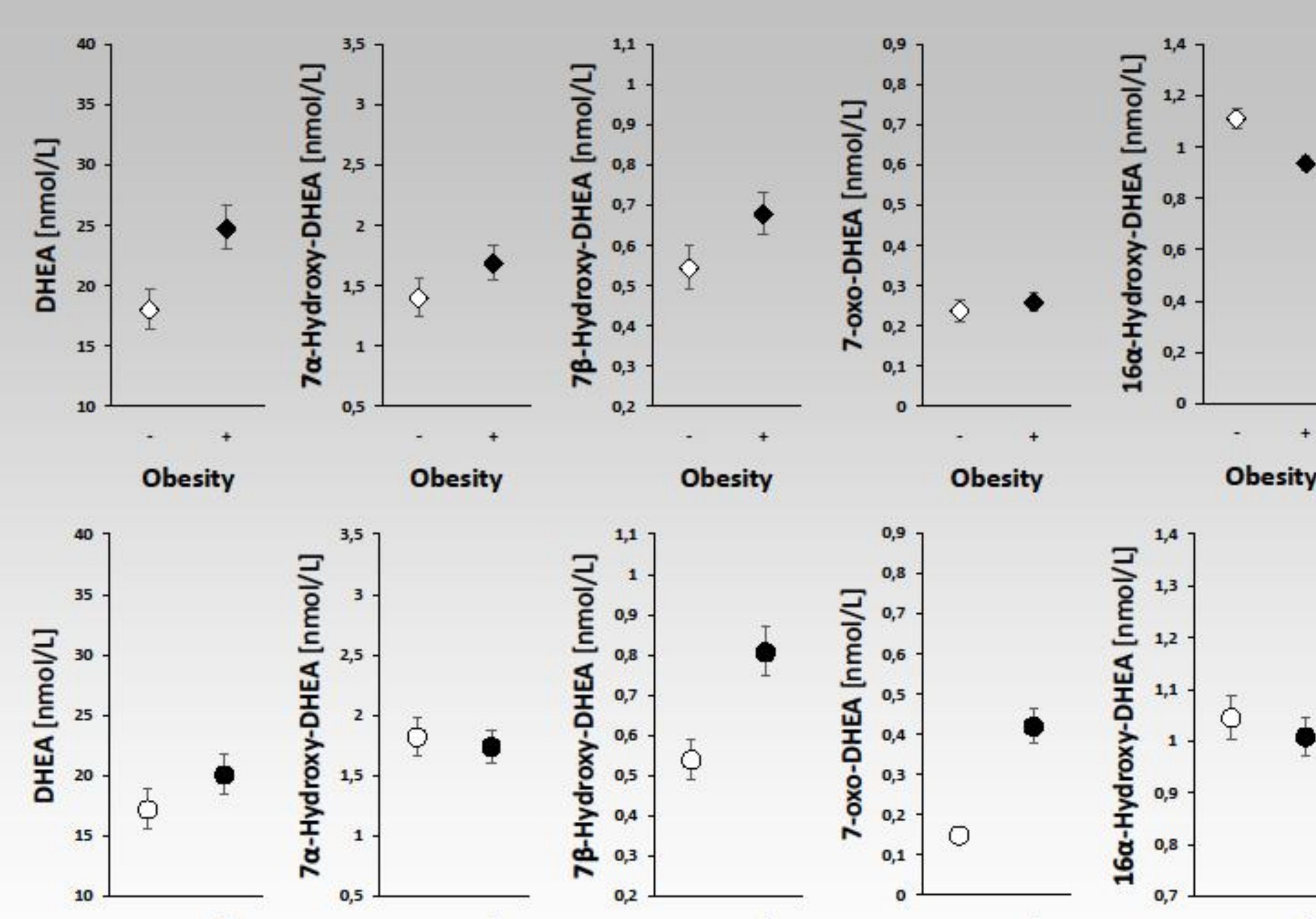

obesity obesity

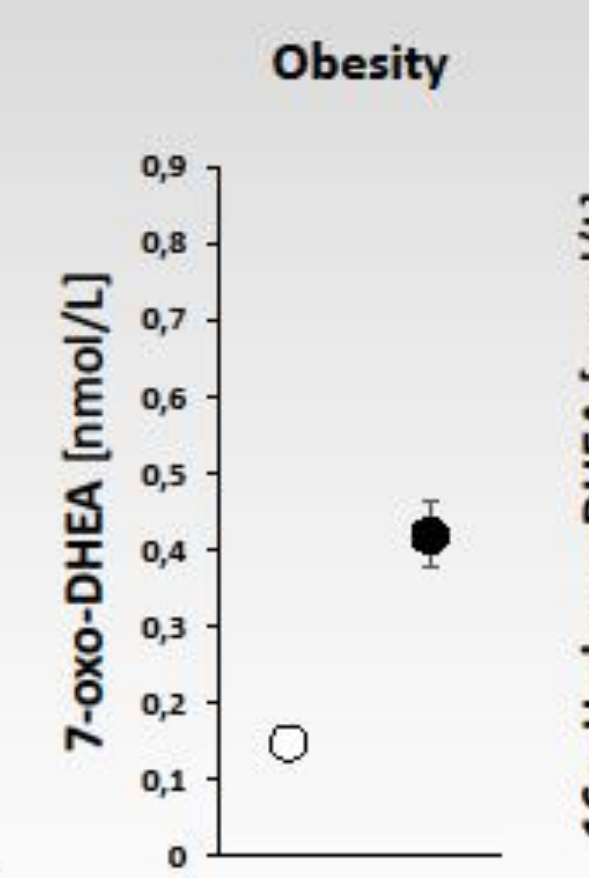

\section{Acknowledgement:}

The study was supported by grants NT 13890-4, NT 12211-5, NT 11277-6 from IGA and DRO (Institute of Endocrinology - EU, 00023761) of the Czech Ministry of Health. 